Плодоводство и виноградарство Юга России № 50(02), 2018 г.

УДК 634.85:631.526.32

DOI: 10.30679 / 2219-5335-2018-2-50-32-39

МУСКАТ КРЫМА ПЕРСПЕКТИВНЫЙ СОРТ ВИНОГРАДА СЕЛЕКЦИИ ИНСТИТУТА «МАГАРАЧ»

Лиховской Владимир Владимирович канд. с.-х. наук

Федеральное государственное бюджетное учреждение науки «Никитский ботанический садНациональный научный иентр» РАН», n. Никита, Ялта, Республика Крым, Россия

Волынкин Владимир Александрович, д-р с.-х. наук, профессор главный научный сотрудник отдела селекции, генетики винограда и ампелографии

Васылык Ирина Александровна канд. с.-х. наук, доцент научный сотрудник отдела селекции, генетики винограда и ампелографии

Полулях Алла Анатольевна канд. с.-х. наук, доцент вед. научный сотрудник отдела селекции, генетики винограда и ампелографии

Федеральное государственное бюджетное учреждение науки «Всероссийский национальный научно-исследовательский институт виноградарства и виноделия «Mazapay» $P A H »$, Ялта, Республика Крым, Россия

Выведение новых столовых сортов винограда раннего срока созревания с нарядной гроздью и крупной ягодой позволит решить проблему повышенного спроса на продукты биологической ценности и ускорит процесс
UDC 634.85:631.526.32

DOI: 10.30679 / 2219-5335-2018-2-50-32-39

\section{MUSKAT OF CRIMEA - A PROMISING GRAPE CULTIVAR OF THE INSTITUTE «MAGARACH» BREEDING}

Likhovskoy Vladimir Vladimirovich

Cand. Agr. Sci.

Federal State Budgetary

Scientific Institution

"Nikitsky Botanical Garden-

National Science Center" RAS"

v. Nikita, Yalta, Republic of the Crimea, Russia

Volynkin Vladimir Aleksandrovich

Dr. Agric. Sci., Professor

Chief Research Associate

of Department of Breeding

and Genetics of grapes and Ampelografy

Vasylyk Irina Aleksandrovna

Cand. Agr. Sci., Docent

Research Associate

of Department of Breeding

and Genetics of grapes and Ampelografy

Polulyakh Alla Anatol'evna

Cand. Agric. Sci.

Leading Research Associate

of Department of Breeding

and Genetics of grapes and Ampelografy

Federal State Budget

Scientific Institution

"All-Russian National

Research Institute

of Viticulture and Winemaking

"Magarach», RAS",

Yalta, Republic of the Crimea, Russia

The creating of new grape table varieties of early ripening with a smart bunch and large berries will solve the problem of increased demand for products of biological value and will accelerate the process of import substitution. 
импортозамещения. Особо это актуально, поскольку позволит обеспечить свежим виноградом отечественного производства на рынке с дефицитом фруктов и ягод в ранний летний период и в курортный сезон жителей и гостей Крыма и других регионов Российской Федерации. При изучении крупноягодных столовых форм винограда очень раннего срока созревания по результатам исследований в 2013-2017 гг. была выделена в элиту гибридная форма из популяции сеянцев Подарок Запорожья х Ливия Магарач № ПЗЛ-1 под рабочим названием Мускат Крыма.

В статье представлены основные ампелографические и биологохозяйственные параметры, которыми характеризуется новый перспективный сорт. Очень ранний срок созревания (5 августа), продукционный период - 110 дней. Устойчивость к морозам до минус $24^{\circ} \mathrm{C}$. Рекомендуемая форма ведения куста - двуплечий кордон с высотой штамба 80-100 см. Нагрузка на куст - 24 глазка; на плодовой лозе 8 глазков. Схема посадки - 3 х 1,5 м. Профилактические обработки против грибных болезней - 3-4 раза в сезон. Установлена высокая морозоустойчивость (до минус $24^{\circ} \mathrm{C}$ ) элитной формы Мускат Крыма по сравнению с контрольным сортом Кардинал. Новый сорт отличается высоким качеством урожая при посадке на хорошо освещенных теплых склонах. Возделывание сорта Мускат Крыма в условиях Южного берега Крыма позволит получать чистую прибыль с 1 га насаждений 1971,8 тыс. руб. ежегодно.

Ключевые слова: СЕЯНЕЦ, ЭЛИТНАЯ ФОРМА, ПРОДУКТИВНОСТЬ, КАЧЕСТВО УРОЖАЯ, ОЧЕНЬ РАННИЙ СРОК СОЗРЕВАНИЯ.
This is especially important since it will allow to ensure by fresh grapes of domestic production the market with a deficit of fruits and berries in the early summer period and in the holiday season of residents and guests of the Crimea and other regions of the Russian Federation. The study of promising grape types conducted during the years 2012-2015 allowed us to single out as elite a hybrid form from the seedlings population of Podarok Zaporojya x Livia - Magarach № PZL-1 with the working title Muskat of Cramea. The article outlines the main ampelographic and bio-economic parameters characterizing this promising new variety.Very early maturity (August 5), production period - 110 days. Resistance to frost up to minus $24^{\circ} \mathrm{C}$. The recommended bush training is a double-arm cordon with trunk height of $80-100 \mathrm{~cm}$. The recommended load on the bush is 24 eyes; load per fruit shoot is 8 eyes. The planting scheme is $3 \times 1.5 \mathrm{~m}$. Prophylactic treatment against fungal diseases is required 3-4 times per season. The high frost resistance (up to minus $24^{\circ} \mathrm{C}$ ) of the elite form of Muscat of Crimea is established in comparison with the control Cardinal grapes. The new variety is characterized by high quality of the crop when it planted on well-lit warm slopes. Cultivation of grapevine cv Muskat of Cramea in the conditions of the Southern coast of the Crimea will allow obtaining 1971.8 thousand rubles net income from a hectare of plantation annually.

Key words: SEEDLING, ELITE FORM, PRODUCTIVITY, QUALITY OF YIELD, SUPER EARLY RIPENING

Введение. Практически вся территория юга России, где традиционно возделывается виноград, является рекреационной зоной и, следовательно, требует бережного отношения к окружающей среде для полноценного 
Плодоводство и виноградарство Юга России № 50(02), 2018 г.

поддержания здоровья людей. Выведение новых столовых сортов винограда раннего срока созревания с нарядной гроздью и крупной ягодой позволит решить проблему повышенного спроса на продукты биологической ценности и ускорит процесс импортозамещения.

Особо это актуально, поскольку позволит обеспечить свежим виноградом отечественного производства на рынке с дефицитом фруктов и ягод в ранний летний период и в курортный сезон жителей и гостей Крыма, и других регионов Российской Федерации [1].

В результате многолетней работы при выполнении госзадания на тему «Определение закономерностей наследования сопряженности степени выраженности селектируемых признаков продуктивности, качества и устойчивости к стресс-факторам для выведения новых сортов винограда» выведен новый сорт винограда Мускат Крыма (Магарач № ПЗЛ-1) столового направления использования, отличающийся от сорта эталона Кардинал очень ранним сроком созревания, высокой продуктивностью, высокой устойчивостью к биотическим и абиотическим стресс-факторам биосферы, нарядной крупной гроздью и ягодой, высоким качеством свежего винограда. Сорт выделен из популяции сеянцев, полученных от скрещивания сортов Подарок Запорожья х Ливия $[1,2]$. Генеалогическая схема выведения сорта представлена на рис. 1.

Обсуждение результатов. Проведенные исследования позволили описать ампелографические признаки и установить агробиологические характеристики нового сорта винограда Мускат Крыма.

Основные ампелографические характеристики. Верхушка молодого побега полностью открытая, слабо опушена, с антоциановыми полосами по краю. Молодой лист светло-зеленый с антоциановыми пятнами. Нижняя поверхность листа покрыта короткими щетинками. 


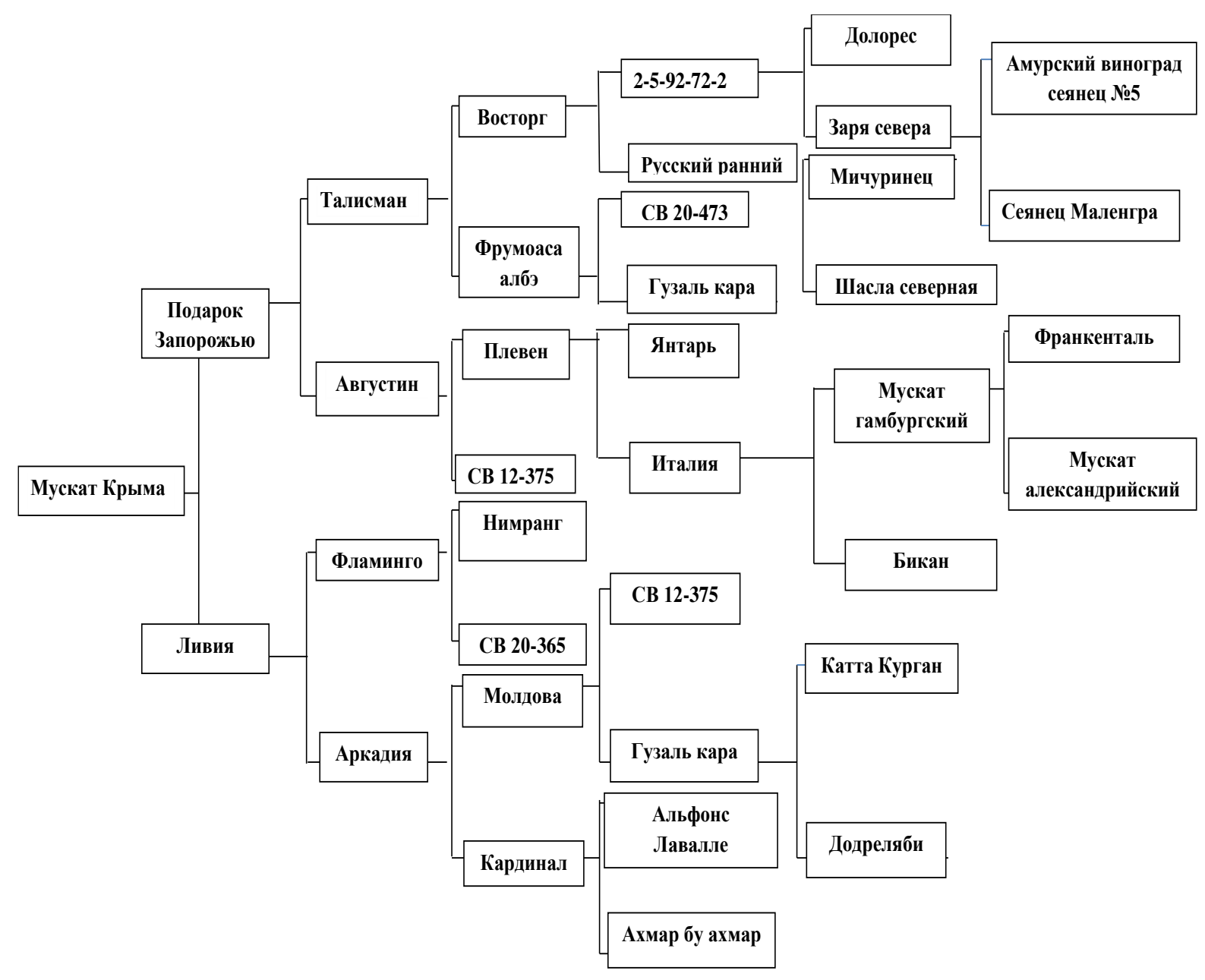

Рис.1. Генеалогия сорта винограда Мускат Крыма

Лист средний, пятиугольный, глубоко рассеченный, пяти-лопастный, со слегка вытянутой в длину центральной лопастью. Верхняя поверхность светло-зеленая, слабо сетчато-морщинистая. Верхние вырезки глубокие, закрытые, с перекрывающимися лопастями и U-образным дном. Нижние вырезки неглубокие, в виде входящего угла. Черешковая выемка закрытая с перекрывающимися лопастями и яйцевидным просветом, реже со слегка соприкасающимися лопастями, с U-образным дном. Дно черешковой выемки ограничено жилками. Зубчики центральных лопастей и по краю листа крупные куполовидные. Нижняя поверхность листа покрыта густыми короткими щетинками. Центральные жилки не имеют антоциановой 
окраски, на нижней поверхности листа покрыты густыми щетинками. Черешок окрашен в светло-фиолетовый цвет, короче центральной жилки.

Тип цветка обоеполый. Гроздь очень большая, ветвистая, рыхлая (рис. 2).

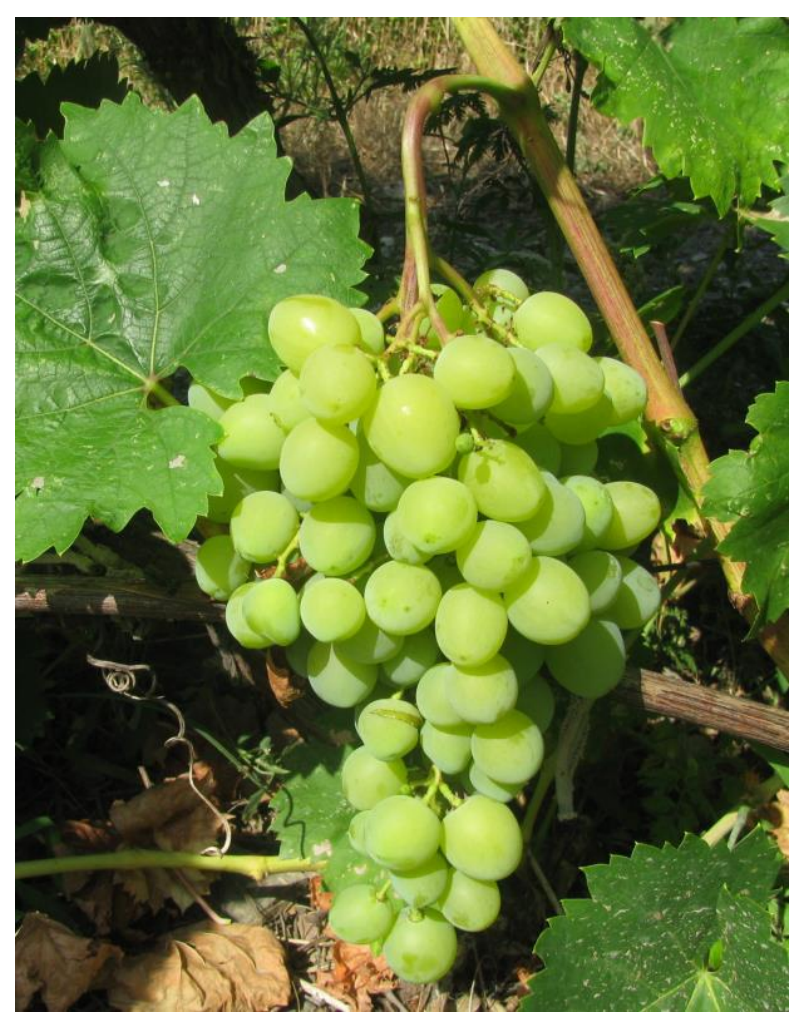

Рис.2. Гроздь сорта винограда Мускат Крыма

Ягода очень крупная, тупояйцевидная, желто-розовая. Мякоть мясистая, с выраженным ароматом муската во вкусе. Семена средние - 2-3 шт. Сорт Мускат Крыма относится к сортам столового направления использования, очень раннего срока созревания для потребления в свежем виде (табл. 1).

Среднемноголетняя дата начала распуская почек в условиях Южного берега Крыма - 18.04. Промышленная зрелость ягод наступает 5 августа. Соответственно, число дней от начала распускания почек до съемной зрелости ягод у сорта Мускат Крыма составляет 110 дней. 
Таблица 1 - Хозяйственно-биологические характеристики сорта винограда Мускат Крыма

\begin{tabular}{|c|c|c|}
\hline Показатель & Мускат Крыма & Кардинал \\
\hline Период созревания ягод & очень ранний & ранний \\
\hline $\begin{array}{l}\text { Даты наступления: } \\
\text { - распускания почек } \\
\text { - технической зрелости ягод }\end{array}$ & $\begin{array}{l}18.04 \\
05.08\end{array}$ & $\begin{array}{l}20.04 \\
20.08\end{array}$ \\
\hline $\begin{array}{l}\text { Продолжительность } \\
\text { продукционного периода }\end{array}$ & 110 & 126 \\
\hline Вызревание однолетних побегов & хорошее & удовлетворительное \\
\hline Рост кустов & средний & средний \\
\hline $\begin{array}{l}\text { Устойчивость сорта к морозам } \\
\text { (какие температурные минимумы } \\
\text { переносит сорт) }\end{array}$ & $-24,0^{0} \mathrm{C}$ & $-18,0^{0} \mathrm{C}$ \\
\hline $\begin{array}{l}\text { Полная гибель почек в глазках } \\
\text { после перезимовки }\end{array}$ & $15 \%$ & $68 \%$ \\
\hline $\begin{array}{l}\text { Поражаемость и повреждаемость } \\
\text { сорта в годы максимального } \\
\text { развития (балл/ \%): } \\
\text { - оидиум } \\
\text { - милдью } \\
\text {-серая гниль } \\
\text {-гроздевая листовертка }\end{array}$ & $\begin{array}{l}3 / 20 \\
3 / 22 \\
3 / 20 \\
3 / 15\end{array}$ & $\begin{array}{l}4 / 55 \\
4 / 55 \\
5 / 78 \\
4 / 60\end{array}$ \\
\hline
\end{tabular}

В результате экспериментальных исследований по промораживанию лозы [3] установлена высокая морозоустойчивость (до минус $24^{\circ} \mathrm{C}$ ) элитной формы Мускат Крыма по сравнению с контрольным сортом Кардинал (см. табл. 1). Сорт Мускат Крыма отличается высоким качеством урожая при посадке на хорошо освещенных теплых склонах (табл. 2).

При проведении органолептической оценки свежий виноград сорта Мускат Крыма, охарактеризован следующим образом: выдающиеся по красоте и форме грозди, нарядные, типичные для сорта; ягоды крупные, тупояйцевидные, некоторые - с легкой розовинкой; вкус гармоничный с ярко выраженным мускатным ароматом; мякоть мясистая, кожица едва ощутима при еде. Средний балл - 9,1. 
Плодоводство и виноградарство Юга России № 50(02), 2018 г.

Таблица 2 - Показатели продуктивности и качества урожая сорта винограда Мускат Крыма

\begin{tabular}{|c|c|c|c|c|c|c|c|c|c|c|}
\hline \multirow{2}{*}{ Сорт } & \multicolumn{4}{|c|}{ Мускат Крыма } & \multicolumn{4}{|c|}{ Кардинал } & \multirow{2}{*}{\multicolumn{2}{|c|}{$\mathrm{HCP}_{05}$}} \\
\hline & 2015 & 2016 & 2017 & $\overline{\mathrm{x}}$ & 2015 & 2016 & 2017 & $\overline{\mathrm{x}}$ & & \\
\hline \multicolumn{11}{|l|}{ Урожайность: } \\
\hline - с 1 куста, кг & 9,9 & 10,8 & 11,0 & 10,6 & 8,1 & 8,2 & 8,5 & 8,3 & 0,3 & $\mathbf{F}_{\mathrm{v}}>\mathbf{F}_{05}$ \\
\hline - с гектара, ц/га & 151 & 160 & 162 & 157 & 121 & 124 & 130 & 125 & 5,7 & $\mathbf{F}_{\mathrm{v}}<\mathbf{F}_{05}$ \\
\hline $\begin{array}{l}\text { Средняя масса } \\
\text { грозди, г }\end{array}$ & 550 & 575 & 561 & 560 & 467 & 498 & 470 & 478 & 13,3 & Fv $>$ F05 \\
\hline $\begin{array}{l}\text { Максимальная } \\
\text { масса грозди, г }\end{array}$ & 615 & 620 & 633 & 623 & 540 & 510 & 498 & 516 & 18,4 & Fv $<$ F05 \\
\hline $\begin{array}{l}\text { Средняя масса } \\
\text { ягоды, г }\end{array}$ & 5,8 & 6,2 & 6,0 & 6,0 & 4,9 & 5,0 & 5,2 & 5,0 & $\mathbf{0 , 3}$ & $\mathbf{F}_{\mathbf{v}}<\mathbf{F}_{05}$ \\
\hline $\begin{array}{l}\text { Максимальная } \\
\text { масса ягоды, г } \\
\end{array}$ & 6,4 & 6,8 & 6,7 & 6,6 & 5,4 & 6,2 & 6,0 & 5,9 & 0,2 & $\mathbf{F}_{\mathbf{v}}<\mathbf{F}_{05}$ \\
\hline \multicolumn{11}{|l|}{$\begin{array}{l}\text { Содержание } \\
\text { в ягодах } \\
\text { при их съемной } \\
\text { зрелости: } \\
\end{array}$} \\
\hline \begin{tabular}{|l} 
- сахаров, \\
$\Gamma / 100 \mathrm{~cm}^{3}$
\end{tabular} & 17,5 & 17,8 & 19,0 & 18,1 & 18,0 & 17,8 & 17,7 & 17,8 & 0,2 & $\mathbf{F}_{\mathbf{v}}<\mathbf{F}_{05}$ \\
\hline $\begin{array}{l}\text {-титруемых } \\
\text { кислот, г/дм }{ }^{3} \\
\end{array}$ & 7,1 & 6,8 & 6,4 & 6,8 & 7,4 & 7,0 & 7,4 & 7,3 & 0,4 & $F_{v}>F_{05}$ \\
\hline $\begin{array}{l}\text { Дегустационная } \\
\text { оценка свежего } \\
\text { винограда, балл }\end{array}$ & 9,2 & 9,0 & 9,2 & 9,1 & 9,0 & 8,8 & 8,9 & 8,9 & $\mathbf{0 , 3}$ & $\mathbf{F}_{v}<\mathbf{F}_{05}$ \\
\hline
\end{tabular}

Рекомендуемая форма ведения куста - двуплечий кордон с высотой штамба 80-100 см. Нагрузка на куст 24 глазка; на плодовой лозе 8 глазков. Схема посадки - 3х2 м. Профилактические обработки против грибных болезней $-3-4$ раза в сезон $[4,5]$.

Таблица 3 - Расчетный экономический эффект возделывания
сорта винограда Мускат Крыма (с 1 га)

\begin{tabular}{|c|c|c|c|c|c|c|}
\hline $\begin{array}{c}\text { Сорт, } \\
\text { элитная форма }\end{array}$ & 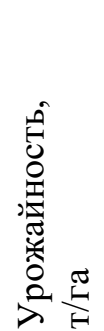 & 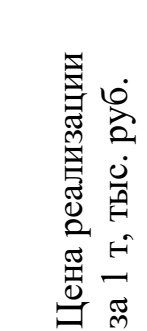 & 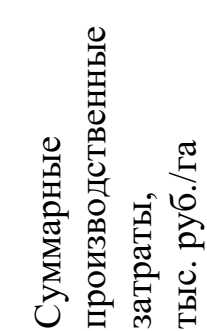 & 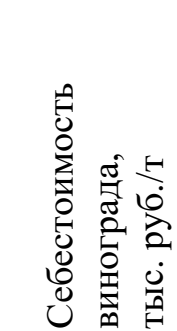 & 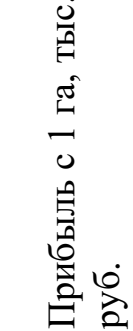 & 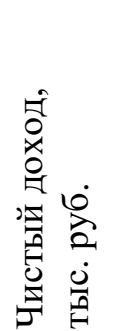 \\
\hline Кардинал (к) & 12,5 & 120,0 & 226,2 & 18,10 & 1500,0 & 1481,9 \\
\hline Мускат Крыма & 15,7 & 140,0 & 226,2 & 14,41 & 2198,0 & 1971,8 \\
\hline
\end{tabular}


Плодоводство и виноградарство Юга России № 50(02), 2018 г.

Таким образом, возделывание сорта винограда Мускат Крыма в условиях Южного берега Крыма позволит получать ежегодно чистую прибыль с 1 га насаждений в размере 1971,8 тыс. руб. (табл. 3).

\section{Литература}

1. Отчет о НИР (ФАНО России). Изучить скрещиваемость крымских аборигенных сортов винограда со сложными межвидовыми гибридами и закономерности наследования силы роста и оидиумоустойчивости. Оценить водно-солевой режим сортов винограда in vivo и in vitro. Исследовать отобранные перспективные интродуцированные сорта табака, пригодные для выращивания в условиях Предгорной зоны Крыма, провести сравнительную оценку интродуцированных сортов с местными сортами для получения перспективных гибридных форм [Текст] ФГБУН «ВННИИВиВ «Магарач»РАН»; рук. Лиховской В.В, Рыфф И.И., Илюхина В.В.; исп. Зленко В.А. и др. Ялта, 2016. - 103с., - № ГР АААА-А-17-1170118100-56-1.

2. Лиховской, В.В. Выявление новых доноров морозоустойчивости при селекции столовых сортов винограда / В.В. Лиховской, В.А. Зленко, И.А. Васылык, А.А. Полулях, В.А. Волынкин // Труды Кубанского государственного аграрного университета. - 2017. - № 67. - С. 135-140.

3. Черноморец М.В. Устойчивость виноградного растения к низким температурам / М.В. Черноморец. - Кишинев: КартяМолдовеняскэ, 1985. - 190 с.

4. Лиховской, В.В. Оценка эффективности возделывания столового винограда ранних сроков созревания в закрытом грунте / В.В. Лиховской, И.А. Васылык, В.В. Петрашко // Плодоводство и виноградарство юга России. - 2016. - №41(05). - С.87-98.

5. Лиховской, В.В. Наследование устойчивости к оидиуму при выведении столовых сортов винограда / В.В. Лиховской, В.А. Волынкин, Н.П. Олейников, И.А. Васылык // Русский виноград. - 2016. - Т. 3. - № 3. - С. 30-37.

\section{References}

1. Otchet o NIR (FANO Rossii). Izuchit' skreshhivaemost' krymskih aborigennyh sortov vinograda so slozhnymi mezhvidovymi gibridami i zakonomernosti nasledovanija sily rosta i oidiumoustojchivosti. Ocenit' vodno-solevoj rezhim sortov vinograda in vivo i in vitro. Issledovat' otobrannye perspektivnye introducirovannye sorta tabaka, prigodnye dlja vyrashhivanija v uslovijah Predgornoj zony Kryma, provesti sravnitel'nuju ocenku introducirovannyh sortov s mestnymi sortami dlja poluchenija perspektivnyh gibridnyh form [Tekst] FGBUN «VNNIIViV «Magarach»RAN»; ruk. Lihovskoj V.V, Ryff I.I., Iljuhina V.V.; isp. Zlenko V.A. i dr. - Jalta, 2016. - 103 s., - № GR AAAA-A-17-1170118100-56-1.

2. Lihovskoj, V.V. Vyjavlenie novyh donorov morozoustojchivosti pri selekcii stolovyh sortov vinograda / V.V. Lihovskoj, V.A. Zlenko, I.A. Vasylyk, A.A. Poluljah, V.A. Volynkin // Trudy Kubanskogo gosudarstvennogo agrarnogo universiteta. - 2017. - № 67. - S. 135-140.

3. Chernomorec M.V. Ustojchivost' vinogradnogo rastenija k nizkim temperaturam / M.V. Chernomorec. - Kishinev: KartjaMoldovenjaskje, 1985. - $190 \mathrm{s.}$

4. Lihovskoj, V.V. Ocenka jeffektivnosti vozdelyvanija stolovogo vinograda rannih srokov sozrevanija v zakrytom grunte / V.V. Lihovskoj, I.A. Vasylyk, V.V. Petrashko // Plodovodstvo i vinogradarstvo juga Rossii. - 2016. - №41 (05). - S.87-98.

5. Lihovskoj, V.V. Nasledovanie ustojchivosti k oidiumu pri vyvedenii stolovyh sortov vinograda / V.V. Lihovskoj, V.A. Volynkin, N.P. Olejnikov, I.A. Vasylyk // Russkij vinograd. - 2016. - T. 3. - № 3. - S. 30-37. 